\title{
Relationship between Cataract and Metabolic Syndrome among African Type 2 Diabetics
}

\author{
Mvitu-Muaka M ${ }^{1}$, Longo-Mbenza $\mathrm{B}^{2 *}$ and Nkondi Mbadi A Nsungu $\mathrm{J}^{3}$
}

${ }^{1}$ Department of Ophthalmology, University of Kinshasa, DR Congo, South Africa

${ }^{2}$ Research Champion Professor, Walter Sisulu University, Faculty of health Sciences, Mthatha, Eastern Cap, South Africa

${ }^{3}$ Service of Ophthalmology, General Hospital of Kinshasa, DR Congo, South Africa

\begin{abstract}
Objectives: This study was performed to evaluate the prevalence and risk diabetics factors of cataracts in type 2 diabetics. The association between advanced diabetic retinopathy, vision loss and cataracts was also investigated among patients with diabetic retinopathy.
\end{abstract}

Methods: This was a community-based and analytic cross-sectional survey among 300 patients (males: 113 , mean age: $58 \pm 12$ years).

Results: One hundred forty patients $(46.7 \%)$ had cataracts versus 95 patients $(32 \%)$ with diabetic retinopathy $(82$ non proliferative and 13 proliferative).

Male sex, maculopathy, smoking, total and abdominal obesity, aging, uncontrolled diabetes, longer duration and high socioeconomic status were the univariate risk factors of cataracts. Only total obesity was the strong, significant and independent determinant of cataracts. There was a significant association between cataracts and blindness in the total study population. Among patients with diabetic retinopathy, those with proliferative diabetic retinopathy were older and presented higher frequency of metabolic syndrome, blindness, visual impairment and cataracts than their counterparts with non proliferative diabetic retinopathy. In patients with diabetic retinopathy, only aging, total obesity, cataract, and smoking were individually and significantly associated with visual impairment.

Conclusion: The prevalence of cataracts among these African type 2 diabetics was $46.7 \%$. Total obesity was a strong independent determinant of the presence of cataracts. The removal of total obesity will contribute to prevent the risk of blindness due to cataracts among African type 2 diabetics.

Keywords: Cataracts; Aging; Metabolic syndrome; Smoking; Blindness; Africans; Type 2 diabetes

\section{Introduction}

Clinicians from developed and developing countries are facing a global epidemic of diabetes mellitus (DM), mainly type 2 diabetes (T2DM), driven by escalating rates of obesity and an increasing lifestyle changes such as physical inactivity, cigarette smoking, high fat intake, and excessive alcohol consumption, and low intake of fruits vegetables. Currently, 171 to 246 million people worldwide are affected by diabetes, and this number is likely to increase to $360-380$ million by 2025-2030 [1,2]

The burden of T2DM is driven by both macrovascular, microvascular (diabetic retinopathy), and blindness. Over the last twenty years (1988-2008), the causes of blindness have changed in proportion and actual number. Cataract has remained the major (3967\%) and number one cause of blindness globally, and nationally [3-7]. In West African type 2 diabetics, cataracts are more important cause of vision impairment than is diabetic retinopathy [5].

In general non African populations, DM, impaired fasting glucose, obesity, anti-hypertensive medication, metabolic syndrome, aging, smoking status, arterial hypertension, retinal vessel narrowing, undernutrition (lower body mass index), education, hypercholesterolemia, arthritis, deprivation exposure to low doses of ionizing radiation (X- rays to the face/neck) are known risk factors of the presence of cataract [8-18].

In West African diabetics, both $\mathrm{T} 2 \mathrm{MD}$, early onset of $\mathrm{T} 2 \mathrm{DM}$, and longer duration of diabetes were the most important determinants of cataracts [5].
Although the rates of obesity, DM blindness (12\%) and visual impairment (27\%), life style changes and cardiometabolic diseases constitute already a second burden of the disease [19-22] aside the traditional burden of endemic (malaria, tuberculosis) and pandemic (HIV/AIDS) infections in Democratic Republic of Congo (DRC). This is due to improvements in nutrition, water supplies, sanitation, and measles immunisation coverages in these privileged urban people. In addition, because of the large number of aging diabetics in DRC, cataracts are likely to provoke a heavy public health burden. DM cases community data based on the magnitude, pathogenesis, and complications of cataracts are not yet available in our setting. This lack hampers the identification of preventable causes of cataract and blindness as well the development of efficient prevention and intervention programmes. The aims of this study were i) to determine the prevalence of cataract among African type 2 diabetics; ii) to investigate the relationship between metabolic syndrome or

*Corresponding author: Longo-Mbenza Benjamin, MD, PhD, DSc, Champion Research Professor, Walter Sisulu University, Faculty of Health Sciences Private Bag X1, Mthatha 5117, Eastern Cape, South Africa, Tel: +27732822843 Fax:+27475022101; E-mail: longombenza@gmail.com

Received September 09, 2011; Accepted December 12, 2011; Published December 16, 2011

Citation: Mvitu-Muaka M, Longo-Mbenza B, Mbadi A Nsungu NJ (2011) Relationship between Cataract and Metabolic Syndrome among African Type 2 Diabetics. J Diabetes Metab 2:160 doi:10.4172/2155-6156.1000160

Copyright: (c) 2011 Muaka MM, et al. This is an open-access article distributed under the terms of the Creative Commons Attribution License, which permits unrestricted use, distribution, and reproduction in any medium, provided the original author and source are credited. 
its components and the presence of cataract in these type 2 diabetes mellitus patients.

\section{Materials and Methods}

\section{Design and setting}

A cross-sectional, analytic and community-based survey of T2DM patients $\geq 20$ years of age $(n=3010)$ and managed by 24 Catholic primary care centres for DM in Kinshasa town, capital of DRC, was carried out in November 2004. Kinshasa, the largest city (7 Million inhabitants) enjoys a tropical climate and constitutes an Hinterland with 24 administrative districts. The Catholic health system has established a primary care centre for DM in each district of Kinshasa city. Figure 1 shows the flow chart of the study design. The study protocol was approved by the University of Kinshasa Medical Ethics Committee and the study was performed in full compliance with the Declaration of Helsinki II.

\section{Patients and sampling}

Expected proportion $(\mathrm{P})$ of cataracts was $\geq 0.40$ (5), total Width (W) of confidence Interval was 0.10 , and the sample size read on table across $\mathrm{P}, \mathrm{W}$, and $95 \%$ confidence level was 369 patients arounded to 384 patients (16 patients per district). Sixteen T2DM patients were randomly selected from the list of each district using random digits. Verbal informed consent was obtained from eligible patients after explanation of the study nature and rationale/ significances. All patients who refused to participate in this study, the patients with type 1 diabetes mellitus, and patients who did not complete their comprehensive physical examination were excluded.

\section{Data collection}

The structured and standardized questionnaires used to obtain information during 30 minutes, were adapted from the Blessey study [23].

The questionnaires sought relevant information on age, sex, DM duration, family history of DM, treatment compliance, ethnicity (Kongo, Ngala, Luba, Swahili), cigarette smoking, alcohol intake and socioeconomic status. The questionnaires were tested in a pilot study with 20 patients prior to the main study. Based on their responses and the level of understanding of the questions administered during 30 minutes, some ambiguous or unclear questions were restructured or modified. The researchers interacted with each respondent.

Data were collected during a comprehensive physical examination including anthropometry, blood pressure, Eye examination, and blood laboratory tests.

Weight, height, and waist circumference (WC) were measured in a standardized fashion by trained, certified observers. Height was measured with a portable stadiometer and recorded to the closest $0.1 \mathrm{~cm}$. WC was measured with a non stretchable tape measures to the nearest $0.1 \mathrm{~cm}$. Weight was measured with a Soehnle beam scale (Soenle-Waagen Gmbh Co, Murrhardt, Germany) to the nearest $0.1 \mathrm{Kg}$. All instruments were calibrated once weekly. Blood pressure including systolic blood pressure (SBP) and diastolic blood pressure (DBP), was measured from the right arm of the seated patient after 15 minutes with an electronic validated digital devices (OMRON M7, Intelli/Sense, Kyoto, Japan). Fasting (10-12 overnight fast) blood glucose (hexokinase-glucose-6-phosphate dehydrogenase reaction), triglycerides and HDL-cholesterol were measured on commercially kits (Biomerieux, Marcy l'Etoile, France) and a Hospitex autoanalyzer (Hospitex Diagnostic, Florence, Italy).
Eye examination of each participant included visual acuity measurement, ocular alignment and motility, pupil reactivity and function, visual fields, intraocular pressure, slit lamp examination of the cornea, iris, lens and vitreous, and dilated fundus examination. This fundus examination was detailed and performed at the best possible mydriasis, after dilating the pupils with tropicamide (1\%) and phenylephrine (10\%), using direct ophthalmoscopes. For refraction and visual acuity testing, patients'eyes were first refracted with the AO Reichert SR-IV Programmed Subjective Refractor (AO Reichert Scientific Instruments, Buffalo, NY, USA). This result was refined as necessary with the use of standard subjective refraction techniques. Retinoscopy and trial lenses were used to refract the eyes of patients who could not use the SR-IV. Visual acuity was measured at $4 \mathrm{~m}$ with the use of the charts and light box described by Ferris et al. [24,25].Visual acuity was measured separately for each eye and was defined according to the lowest line on the chart for which the majority of letters were read correctly. Visual acuity was measured twice, first with the patient's typical distance correction (that is, eyeglasses or contact lenses, if any) and again with the full required distance correction as determined by the study refraction data. Best corrected visual acuity was defined as the visual acuity in the better eye with full distance correction. Due to limited resources, retinal photography was excluded as a diagnostic tool. The experience in sub - Saharan Africa demonstrates a better than $80 \%$ concurrence between clinical and photographic assessment of the presence and absence of lesion associated with diabetic retinopathy [5]

\section{Definitions}

Diagnosis of T2DM was based on criteria established by the American Diabetes Association Expert Committee [26]: exhibiting either a fasting plasma glucose concentration of $\geq 126 \mathrm{mg} / \mathrm{dL}(7.0$ $\mathrm{mmol} / \mathrm{L}$ ) on more than one occasion, and / or pharmacological treatment of diabetes. Total obesity was defined by body mass index (weight in $\mathrm{Kg} /$ height in $\mathrm{m}^{2}$ ) $\geq 30 \mathrm{Kg} / \mathrm{m}^{2}$ [27]. Metabolic syndrome (Mets) was diagnosed according to the IDF criteria: $\mathrm{WC} \geq 94 \mathrm{~cm}$ for men, WC $\geq 80 \mathrm{~cm}$ for women, triglycerides levels $\geq 1.7 \mathrm{mmol} / \mathrm{L}$, HDL - Cholesterol $<1.03 \mathrm{mmol} / \mathrm{L}$ (male) or $<1.29 \mathrm{mmol} / \mathrm{L}$ (female), $\mathrm{SBP} \geq$ $130 \mathrm{mmHg}$ or DBP $\geq 85 \mathrm{mmHg}$, or treatment for lipid abnormalities, and fasting plasma glucose $\geq 100 \mathrm{mg} / \mathrm{dL}(5 \mathrm{~mm} / \mathrm{dL}$ [28]. Arterial hypertension was defined as SBP $\geq 140 \mathrm{mmHg}$ or $\mathrm{DBP} \geq 90 \mathrm{mmHg}$ or under antihypertensive drug treatment as recommended by the ISF / WHO guidelines committee [29].

Aging was defined as age $\geq 60$ years. The Intake of $\geq 4$ drinks/ day was considered as excessive alcohol intake. Smoking habits were classified into 2 groups: never smoker and current smoking $\geq 1$ cigarette per day. Longer duration of diabetes was $\geq 3$ years (median).

A diagnosis of diabetic retinopathy (DR) was made only where a patient had a minimum of one microaneurysm in any field, in addition to exhibiting haemorrhages (dot, blot, or flame shaped) and maculopathy (with or without clinically significant macula oedema). For the classification of DR, the modified Airlie House classification as introduced by the Early Treatment Diabetic Retinopathy Study (ETDRS) [30] was used as follows: non proliferative (NPDR), proliferative (PDR) and maculopathy. We defined dilated lens using Lens Opacities Classification System III grading as nuclear $(\geq 4)$, cortical $(\geq 2)$ and posterior subcapsular $(\geq 2)$ cataracts. Aphakic and pseudoaphakic eyes were included as operated cataracts for statistical analysis.

Blindness was defined by visual acuity $<6 / 60$ (TYPES III, IV and $\mathrm{V}$ of disability) using the World Health Organization definition and 
Page 3 of 7

revision of classification [30]. Normal vision was defined by visual acuity between 1.0 and $0.3[6 / 6-6 / 18]$. Uncontrolled diabetes was defined by fasting plasma glucose $\geq 126 \mathrm{mg} / \mathrm{dL}$ at evaluation.

\section{Statistical analysis}

Data were reported as proportions (\%) for categorical variables and means \pm SD for continuous variables. The Chi-square test was used to compare proportions; comparisons of means between groups were performed using the Student $\mathrm{t}$ - test.

The univariate risk of cataracts (non operated + operated) was assessed in calculating Odds ratio (OR) with 95\% confidence intervals (95\% CI). Multivariate analysis such as logistic regression model, was used to assess the independent effect of selected variable on the presence of cataracts after adjusting for the effect of other potential confounders.

A P value $<0.05$ was considered significant. Data analysis was carried out using the Statistical Package for Social Sciences (SPSS) for Windows version 13 (SPSS Inc, Chicago, IL, USA).

\section{Results}

A total of 300 T2DM patients (response rate of $78,1 \%$ ) including 113 males $(37,7 \%)$ and 187 females $(62,3 \%)$ were examined. The mean age of the study population was $58 \pm 12$ years (range $20-83$ years). At the onset of diabetes mellitus, the mean age was $51.9 \pm 12.8$ years. Mean duration of diabetes mellitus was $6 \pm 7$ years with a median of 4 years (range $1-58$ years). The duration of diabetes was very short: median of 3 years. Among these diabetics, 246 patients (82\%) had uncontrolled diabetes.

\section{Cataracts prevalence}

The prevalence of any cataracts including operated eyes was $46,7 \%(\mathrm{n}=140)$ whose $10 \%(\mathrm{n}=14)$ operated, $30 \%(\mathrm{n}=42)$ nuclear, $33 \%(n=46)$ cortical, and $27 \%(n=38)$ posterior subcapsular cataracts. Thus cataracts were commoner than diabetic retinopathy $(32 \% \mathrm{n}=95)$ and maculopathy $(10 \% \mathrm{n}=31)$. Compared to T2DM patients without cataracts, T2DM patients with cataracts were older and had longer diabetes duration, and higher proportion of males, maculopathy, blindness, cigarette smokers, high socioeconomic status (SES), abdominal obesity and total obesity (Tables 1 and 2 ).

The risk of the presence of cataracts was multiplied by two times by males sex (in spite of the orverrepresentation of women), diabetes duration $\geq 3$ years and cigarettes smoking, respectively. Cigarette

\begin{tabular}{|l|l|l|l|}
\hline Variables of interest & $\begin{array}{l}\text { Presence of cataract } \\
\mathbf{n}=\mathbf{1 4 0} \\
\text { Mean } \mathbf{\pm} \text { SD or } \mathbf{n} \text { (\%) }\end{array}$ & $\begin{array}{l}\text { Absence of } \\
\text { cataracts } \mathbf{n = 1 6 0} \\
\text { mean } \mathbf{\pm} \text { SD or } \mathbf{n}(\%)\end{array}$ & $\mathbf{P}$ \\
\hline Age (years) & $64 \pm 9$ & $53 \pm 12$ & 0.0001 \\
\hline Diabetes duration (years) & $7 \pm 7$ & $5 \pm 4$ & 0.0007 \\
\hline Sex & & & $0.002^{*}$ \\
\hline Males & $65(57.5)$ & $48(42.5)$ & \\
\hline Females & $75(40.1)$ & $112(59.9)$ & $<0.0001$ \\
\hline Age $\geq 60$ years & $102(68.9)$ & $46(31.1)$ & 0.022 \\
\hline Abdominal obesity & $(65)$ & $(39)$ & $0.027^{*}$ \\
\hline Total obesity & $(62)$ & $(38)$ & 0.0001 \\
\hline Longer diabetes duration & $86(56.2)$ & $67(43.8)$ & $<0.0001$ \\
\hline Maculopathy & $24(77.4)$ & $7(22.6)$ & 0.005 \\
\hline Blindness & $40(62.5)$ & $24(37.5)$ & 0.012 \\
\hline Cigarette smoking & $29(63)$ & $17(37)$ & 0.016 \\
\hline High SES & $99(51.6)$ & $93(48.4)$ & \\
\hline
\end{tabular}

*significant findings

Table1: Variables associated with the presence of cataracts.

\begin{tabular}{|l|l|l|}
\hline Variables of interest & $\mathbf{O . R}(\mathbf{9 5} \% \mathbf{C l})$ & $\mathbf{P}$ - value \\
\hline Men vs. Women & $\begin{array}{l}2.02 \\
(1.3 \text { to } 3.3)\end{array}$ & $0.005^{*}$ \\
\hline DM duration $\geq 3$ years vs. <3 years & $\begin{array}{l}2.2 \\
(1.4 \text { to } 3.5)\end{array}$ & $<0.001$ \\
\hline $\begin{array}{l}\text { Total obesity } \\
\text { yes vs. no }\end{array}$ & $\begin{array}{l}1.3 \\
(1.04 \text { to } 1.6)\end{array}$ & $0.027^{*}$ \\
\hline $\begin{array}{l}\text { Ageing } \\
\geq 60 \text { years vs. }<60 \text { years }\end{array}$ & $\begin{array}{l}6.7 \\
(4.01 \text { to } 11.03)\end{array}$ & $<0.001$ \\
\hline $\begin{array}{l}\text { Smoking } \\
\text { Yes vs. no }\end{array}$ & $\begin{array}{l}2.2 \\
(1.2 \text { to } 4.2)\end{array}$ & $0.024^{*}$ \\
\hline $\begin{array}{c}\text { SES } \\
\text { High vs. Low }\end{array}$ & $\begin{array}{l}1.3 \\
(1.04 \text { to } 1.6)\end{array}$ & 0.024 \\
\hline
\end{tabular}

Table 2: Univariate risk factors of cataract.

\begin{tabular}{|l|l|l|l|}
\hline Variables & $\begin{array}{l}\text { NPDR } \mathbf{n}=82 \\
\text { Mean } \pm \text { SD or } n(\%)\end{array}$ & $\begin{array}{l}\text { PDR } \mathbf{n}=13 \\
\text { Mean } \pm \text { SD or } n(\%)\end{array}$ & P \\
\hline Age (years) & $56.1 \pm 12.6$ & $62.2 \pm 6.1$ & $0.04^{*}$ \\
\hline DM duration (years) & $8.6 \pm 7.5$ & $11.2 \pm 8.1$ & 0.246 \\
\hline Sex & & & \\
\hline Men & $29(35.4)$ & $4(30.8)$ & 0.746 \\
\hline Women & $53(64.6)$ & $9(69.2)$ & \\
\hline Metabolic syndrome & $21(25.6)$ & $7(53.8)$ & $0.038^{*}$ \\
\hline Blindness & $3(3.7)$ & $3(23.1)$ & $0.007^{*}$ \\
\hline Visual impairment & $17(20.7)$ & $11(84.6)$ & $0.0001^{*}$ \\
\hline Maculopathy & $15(18.3)$ & $5(38.5)$ & 0.097 \\
\hline Cataract & $39(47.6)$ & $10(76.9)$ & 0.049 \\
\hline Smoking & $13(15.9)$ & $4(30.8)$ & 0.192 \\
\hline Alcohol intake & $2(2.4)$ & $0(0)$ & 0.569 \\
\hline
\end{tabular}

Table 3: Characteristics of cases of non proliferative diabetic retinopathy (NPDR) and cases of proliferative diabetic retinopathy (PDR).

\begin{tabular}{|l|l|l|l|}
\hline Variables & $\begin{array}{l}\text { Presence of visual } \\
\text { impairment } \mathbf{n}=\mathbf{2 9} \\
\text { Mean } \pm \text { SD or } \mathrm{n}(\%)\end{array}$ & $\begin{array}{l}\text { Absence of visual } \\
\text { impairment } \mathbf{n}=\mathbf{6 6} \\
\text { Mean } \pm \text { SD or } \mathrm{n}(\%)\end{array}$ & P \\
\hline Age (years) & $60.3 \pm 11.8$ & $50 \pm 12.1$ & $<0.001^{*}$ \\
\hline DM duration (years) & $9.7 \pm 7.2$ & $8.7 \pm 7.7$ & 0.545 \\
\hline Sex & & & 0.332 \\
\hline Men & $8(27.6)$ & $25(37.9)$ & \\
\hline Women & $21(72.4)$ & $41(62.1)$ & 0.445 \\
\hline Family history of DM & $27(93.1)$ & $58(87.9)$ & 0.447 \\
\hline Total obesity & $10(34.5)$ & $21(31.8)$ & 0.680 \\
\hline High SES & $8(27.6)$ & $21(31.8)$ & $<0.01^{*}$ \\
\hline Cataract & $24(82.7)$ & $25(37.7)$ & $0.027^{*}$ \\
\hline Smoking & $9(31)$ & $8(12.1)$ & \\
\hline
\end{tabular}

Table 4: Characteristics of 95 patients with diabetic retinopathy stratified by the presence of visual impairment.

smoking conferred a 7 - fold risk of cataracts, while $30 \%$ of excess of risk for cataracts were determined by both total obesity and high SES. The rest of variables were not associated with the presence of cataracts (results not shown). All patients with cataracts (100\%) were defined by uncontrolled diabetes.

\section{Multivariate analyses}

In logistic regression analysis adjusted for age, gender, diabetes duration, cigarette smoking and SES, only total obesity was significantly and independently associated with the presence of cataracts (Beta coefficient $=2.526$, standard Error $=1.193, \mathrm{OR}=1.395 \% \mathrm{C}, 1.01-1.4$; $\mathrm{P}=0.034)$.

\section{Types of diabetic retinopathy}

Compared with T2DM patients with non proliferative diabetic 

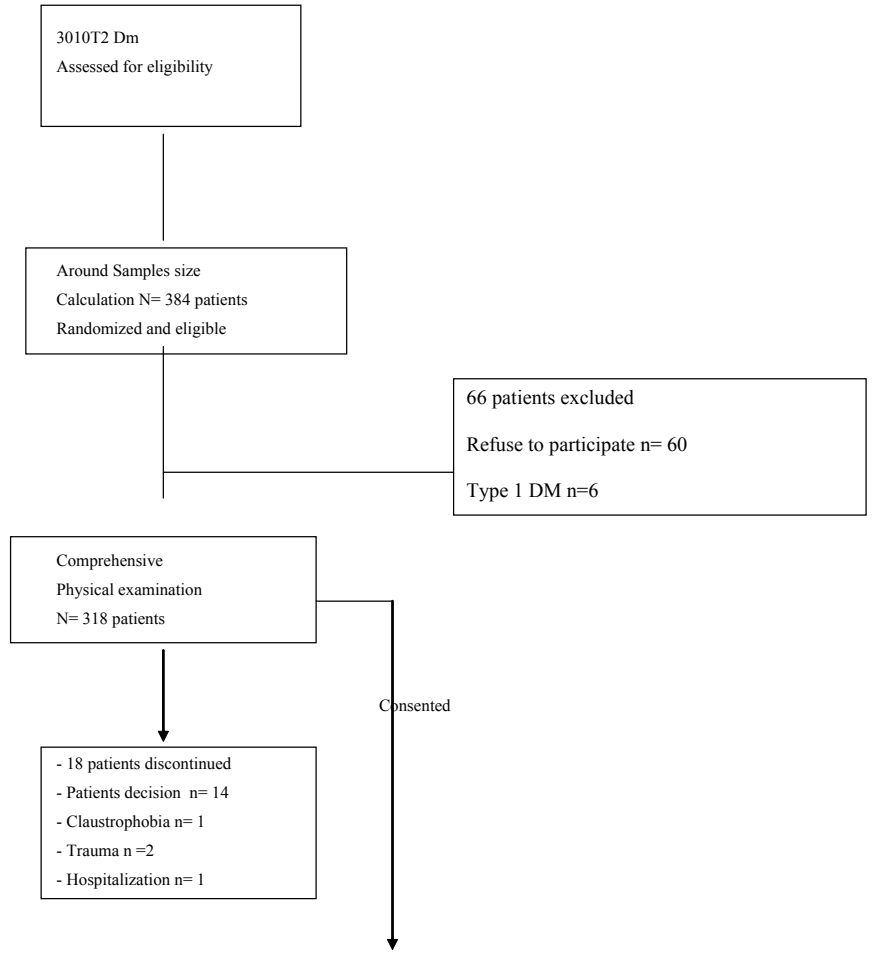

300 patients completed

Figure 1: Flow chart of the study design.

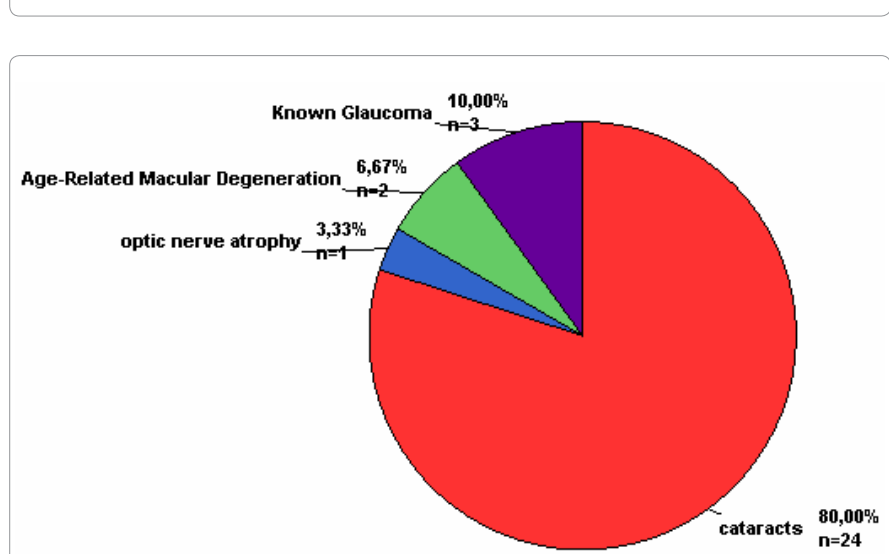

Figure 2: Leading causes of visual impairment among type 2 diabetics with diabetic retinopathy in this study.

retinopathy (NPDR), T2DM patients with proliferative diabetic retinopathy $(\mathrm{PDR})$ were older $(\mathrm{P}<0.05)$ and had higher proportions $(\mathrm{P}<0.05)$ of metabolic syndrome, blindness, visual impairment and cataract (Table 3). In logistic regression and after adjustment for confounders, only cataracts were significantly and independently associated with $\mathrm{PDR}(\mathrm{OR}=3.395 \% \mathrm{CI} 1.06-11 . \mathrm{P}=0.049)$. In all T2DM with diabetic retinopathy, only aging, cataract, and cigarette smoking were significantly and individually associated with the presence of visual impairment $(30 \% \mathrm{n}=29 / 95)$ (Table 4). Among cases of visual impairment with diabetic retinopathy $(n=29), 4 / 5$ cases $(n=24)$ had cataracts as leading cause of blindness (Figure 2).

\section{Discussion}

The present study showed that the prevalence of cataracts was unexpectedly high in these African type 2 diabetics. Cataracts were reported as a main cause of blindness and diabetic retinopathy. The influence of lifestyle changes and metabolic syndrome on cataracts and proliferative diabetic retinopathy formation was also evaluated in these African type 2 diabetics.

\section{Female predominance in the study}

The majority of the participants were females. From 1960, recurrent army conflicts have generated overrepresentation of women in the Congolese populations. Males may be underestimated as the study was carried out during the working day.

\section{Prevalence of cataracts}

The prevalence of cataracts was estimated $46,7 \%$ among these black African type 2 diabetics. This rate is included within the interval of $39-67 \%$ cataracts reported in developed and developing countries [3-7]. This results confirms that cataracts remains the leading cause of the visual loss [3-7].

\section{Risk factors of cataracts}

Aging, male sex, longer duration of diabetes, high SES, cigarette smoking, abdominal obesity, and total obesity were individually associated with the presence of cataracts among these type 2 diabetics as reported elsewhere in Sub-Saharan Africa [8-18]. Male sex, uncontrolled diabetes and maculopathy (advanced diabetic retinopathy) were also significantly associated with the presence of cataracts among these type 2 diabetics. Epidemiologic studies from Europe have also identified long duration of diabetes disease, advanced age at the time of clinical diagnosis, advanced retinopathy and poor control of blood sugar level as risk factors for cataracts in diabetics [3133]. As reported for diabetic Korean patients [34] the higher prevalence of diabetes mellitus was in females and most cases in this study and our previous studies $[22,31,35]$ were also with a shorter duration of diabetes mellitus (median $=3$ years and 4 years).

A recent Korean study among type 2 diabetics showed that advanced age is not a risk factor of cataracts, but females are more common in the cataracts group than the control group [36].

US diabetic women are most likely to have cataracts than are female control [37]. However, the present study showed that the prevalence of diabetic cataracts was higher in males African type 2 diabetics than their female counterparts in spite of the overrepresentation of women.

Sub-Sahara African populations are experiencing sanitary transitions including epidemiologic transition (decrease in rates of non communicable diseases such as type 2 diabetes, hypertension, and obesity), demographic transition (aging), and nutrition transition (appropriate traditional African diet with low intake of salt, sugar, alcohol and fats replaced by Western fast food with low intake of fruits /vegetables and processed with refined sugar, low fibres, high salt and fats). Those sanitary transitions and lifestyle changes such as cigarette smoking, physical inactivity and stress explain the current double, triple or quadruple burden of the disease in Africa [19-21]. These findings may explain the significant high prevalence of cataracts among affluent diabetics (high SES), total obesity and abdominal obesity. The present study shows that there is fairly consistent evidence that cigarette smoking (nicotine) is related to the presence of cataracts as reported from Caucasian [37-39] and Chinese populations [40] 
Although no significant association is noted between cigarette smoking and any particular type of cataract in a rural South Indian population, smokeless tobacco use is found to be significantly associated with nuclear cataract even after adjusting for age and sex [41]. It is well established that the very low sub-micromolar level of nicotine occurring in the tissues of smokers, induces endoplasmic reticulum (ER) stressors (cataractogenic stressors $=\mathrm{Cata} / \mathrm{Er}$ stressors). The Cata/ ER stressors induces the unfolded protein response (UPR), which upregulates caspaces and produces reactive oxygen species (ROS) in lens epithelial cells (LECs). Thus, these caspases and the ROS lead to serious cellular damage, cell death, and cataract [42-46].

\section{Relation between visual acuity, metabolic syndrome, age, cataract, cigarette smoking and proliferative diabetic retinopathy}

Among the present group with diabetic retinopathy ( $\mathrm{n}=95$ including 82 cases of NPDR and 13 cases of PDR), only aging, metabolic syndrome, blindness, visual impairment and cataract were significantly associated with the presence of proliferative DR. Moreover, only aging, cataract and cigarette smoking were significantly associated with the presence of visual impairment in these African type 2 diabetics. This is reasonable because cataracts are the main cause of visual loss (accumulation of reactive oxygen). Studies from literature report that the retinopathy is an influential factor on the degree of cataract [36,4749]. Thus, the present data predict that many African type 2 diabetics will have cataracts and vision loss when their diabetic retinopathy has progressed. Diabetic retinopathy is a vascular complication of diabetes which is strongly influenced by the degree of oxidative stress. Cigarette smoking, aging, and chronic hyperglycemia are risk factors of development of oxidative stress. In addition, PDR is an advanced stage of retinal vascular complication which should be correlated with high degree of oxidative stress.

In multiple regression analysis, we found that only total obesity was the only significant and independent determinant for diabetic cataracts after adjusting for confounding risk factors. The relationship between obesity and cataracts has been investigated in many epidemiological studies, but the findings are not universally consistent. Higher body mass index (BMI) (total obesity) and higher waist to Hip ratio (abdominal obesity) are associated with the presence or incidence of cataracts [37,50-51].

Lower BMI is also associated with cataracts after adjusting for age, sex and other factors [53,54]. Several pathophysiological mechanism have been proposed to explain the association of obesity and cataracts. One theory suggests that leptin, a $16-\mathrm{kD}$ pleiotopic cytokine expressed and secreted mainly by adipocytes [55], is involved in the molecular mechanisms underlying cataract formation [56]. Leptin increases accumulation of reactive oxygen species (oxidative stress) in various cellular models [57]. Indeed hyperleptinemia and leptin resistance [58], systemic oxidative stress [59] and inflammation [60,61] are significantly associated with total obesity. In addition, oxidative stress [62] and inflammation markers [60] may play a pathogenic role in cataract formation. Other data found no association between lower $\mathrm{BMI}$ and age-related cataract [62].

\section{Clinical and public health implications}

The present study supports the hypothesis of Shinohara et al. [63] which states that a cataract can be considered a window that can indicate the presence of systemic disorders such as metabolic syndrome, diabetes mellitus, severe diarrhea, dehydration, vitamin deficiency, viral infections, hypertension, dyslipidemia, heavy metals intoxication, Alzheimer's disease, Parkinson's disease, and insulin resistance.

This is important for health practitioners because cataract is easily detected during a routine ocular examination. Earlier detection of systemic disorders can save the lives of patients. For Public Health perspectives, cataractogenic stressors (smoking, excessive alcohol intake, obesity, metabolic syndrome) from patients with cataracts should be the one of the first steps for the prevention and treatment of advanced diabetic retinopathy, vision loss, and systemic disorders. The control of hyperglycemia should be the second step for prevention of cataracts

\section{Limitations}

The present study is limited to demonstrate causality because of cross-sectional design. Prospective studies are recommended. It was not possible to demonstrate whether weight loss reduces the risk of cataracts. The limited resources in the study setting did not allow indirect ophthalmoscopy, systematic tonometry and the measurement of blood levels of lipids, C-reactive protein, fibrinogen, $\mathrm{HbA1c}$, and oxidative stress markers.

\section{Conclusion}

Cataracts remain a leading cause of vision loss in these African type 2 diabetics. Presence of cataract was significantly associated with uncontrolled diabetes, male sex, longer duration of diabetes, abdominal obesity, total obesity, cigarette smoking advanced retinopathy and high socioeconomic status. The removal of total obesity, the strong independent determinant of the presence of cataracts, and cigarette smoking in type 2 diabetics will contribute to present risk of blindness related to diabetes. All diabetics with cataract should need comprehensive medical and eyes examinations.

\section{References}

1. Widd S, Roglic G, Green A, Sicree R, King H (2004) Global prevalence of diabetes. Estimates for years and projection for 2030. Diabetes Care 27: $1047-$ 1053.

2. www. idf.org. Accessed June 2009

3. Foster A, Gilbert C, Johnson G (2008) Changing patterns in global blindness: 1988- 2008. Community Eye Health 21: 37-39

4. Rodriguez J, Sanchez R, Munoz B, West SK, Broman A, et al. (2002) Causes of blindness and visual impairment in a population-based sample of U.S Hispanics. Ophthalmology 109: 737-743.

5. Rotimi C, Daniel H, Zhou J, Obisesan A, Chen G, et al. (2003) Prevalence and determinants of diabetic retinopathy and cataracts in West African Type 2 Diabetes Patients. Ethn Dis 13: S110-117.

6. Cotter SA, Varma R, Ying-Lai M, Azen SP, Klein R, et al. (2006) Causes of Low vision and blindness in adult Latinos: the Los Angeles Latino Eye Study. Ophthalmology 113: 1574-1582.

7. Schémann JF, Inocencio F, de Lourdes Monteiro M, Andrade J, Auzemery A, et al. (2006) Blindness and low vision in Cape Verde Islands: results of a national eye survey. Ophthalmic Epidemiol 13: 219-226.

8. Paunksnis A, Bojarskiene F, Cimbalas A, Cerniauskiene LR, Luksiene DI, et al. (2007) Relation between cataract and metabolic syndrome and its components. Eur J Ophthalmol 17: 605-614.

9. Navarro Esteban JJ, Gutiérrez Leiva JA, Valero Caracena N, Buendia Bermeio J, Calle Puron ME, et al. (2007) Prevalence and risk factors of lens opacities in the elderly in Cuenca, Spain. Eur J Ophthalmol 17: 29-37.

10. Bojarskiene F, Cerniauskiene LR, Paunksnis A, Luksiene DI (2006) Association of metabolic syndrome components with cataract. Medicina (Kaunas) 42: 115 
11. Habot - Wilner Z, Belkin M (2005) Obesity is a risk factor for eye diseases. Harefuah 144: 805-809, 821.

12. Tan JS, Wang JJ, Mitchell $P$ (2008) Influence of diabetes and cardiovascula disease on the long-term incidence of cataract: the Blue Mountains eye study. Ophthalmic Epidemiol 15: 317-327.

13. Shah SP, Dincen B, Jadoon Z, Bourne R, Khan MA, et al. (2007) Lens opacities in adults in Pakistan: prevalence and risk factors. Ophthalmic Epidemiol 14 381-389.

14. Tan AG, Mitchell P, Burlutsky G, Rochtchina E, Kanthan G, et al. (2008) Retina vessel caliber and the long- term incidence of age-related cataract: the Blue Mountains Eye Study. Ophthalmology 115: 1693-1698.

15. Tan JS, Wang JJ, Younan C, Cumming RG, Rochtchina E, et al. (2008) Smoking and the long-term incidence of cataract: the Blue Mountains Eye study. Ophthalmic Epidemiol 15: 155-161.

16. Athanasiov PA, Casson RJ, Sullivan T, Newland HS, Shein WK, et al. (2008) Cataract in rural Myanmar: prevalence and risk factors from the Meiktila Eye Study. Br J Ophthalmol 92: 1169-1174.

17. Chodick G, Bekiroglu N, Hauptmann M, Alexander BH, Freedman DM, et al. (2008) Risk of cataract after exposure to low doses of ionizing radiation: a 20 year prospective cohort study among US radiologic technologists. Am J Epidemiol 15: 620-631.

18. Ning Cheung, Tien Y, Wong F (2007) Obesity and Eye Diseases. Sur Ophthalmol 52: 180-195

19. Kasiam Lasi On'kin JB, Longo-Mbenza B, Nge Okwe A, Kangola Kabangu N (2007) Survey of abdominal obesities in an adult urban population of Kinshasa, Democratic Republic of Congo. Cardiovasc J Afr 18: 300-307.

20. Longo-Mbenza B, Vangu Ngoma D, Nahimana D, Mayuku DM, Fuele SM, et al. (2008) Screen detection and the WHO Stepwise approach to the prevalence and risk factors of arterial hypertension in Kinshaha. Eur J Cardiovasc Prev Rehabil 15: 503-508.

21. Kasiam Lasi On'Kin JB, Longo-Mbenza B, Nge Okwe, Kabangu NK, Mpandamadi SD, et al. (2008) Prevalence and risk factors of diabetes mellitus in Kinshasa Hinterland. Int J Diabetes \& Metabolism 16: 97-106.

22. Mvitu M, Kimenyembo W, Kaimbo wa Kaimbo D, Dirven W, Muls E (2006) Frequency of visual impairment and blindness in Congolese people with diabetes. Diabetic Medecine 23: 608-675.

23. Blessey R (1985) Epidemiology, risk factors, and pathophysiology of ischemic heart. Physical Ther 65: 1796-1805

24. Ferris FL, Kassoff A, Bresnick GH, Baely I (1982) New visual acuity charts for clinical research. Am J Ophthalmol 94: 91-96.

25. Ferris FL III, Sperduto RD (1982) Standardized illumination for visual acuity testing in clinical research. Am J Ophthalmol 94: 97-98.

26. American Diabetes Association (1992) Screening for type 2 diabetes. Diabetes Care 22: S20-S23.

27. Physical status: the use and interpretation of anthropometry (1995) Report of a WHO Expert Commitee. World Health Organ Tech Rep Ser 854: 1-452.

28. Alberti KG, Zimmet P, Shaw J (2005) The metabolic syndrome -- a new worldwide definition. Lancet 366: 1059 - 1062

29. (1999) 1999 World Health Organisation / International Society of hypertension guidelines for the management of hypertension. Guidelines subcommittee. J Hypertens 17: 151-183

30. Dandona L, Dandona R (2006) Revision of visual impairment definitions in the International Statistical Classification of Diseases. BMC Med 4: 7 .

31. Klein BE, Klein R, Moss SE (1985) Prevalence of cataracts in a population based study of persons with diabetes mellitus. Ophthalmology 92: 1191-1196.

32. West SK, Valmadrid CT (1995) Epidemiology of risk factors for age-related cataract. Surv Ophthalmol 39: 323-334.

33. Bron AJ, Sparrow J, Brown NAP, Harding JJ, Blakytny R (1993) The lens in diabetes. Eye 7: 260-275

34. Nam JW, Rhee MG (1982) Clinical study on diabetic cataract. J Korean Ophthalmol Soc 23: 533-539.

35. Longo- Mbenza B, Nkondi Mbadi A Nsungu J, Mbungu Fuele S (2008) Higher pulse pressure, systolic arterial hypertension, duration of diabetes and family history of diabetes in Central Africans. Int J Diabetes \& Metabolism 16: 17-23.

36. Kim SI, Kim SJ (2006) Prevalence and risk factors for cataracts in persons with type 2 diabetes mellitus. Korean J Ophthalmol 20: 201-204.

37. Jacques PF, Moeller SM, Hankinson SE, Chylack LT, Rogers G, et al. (2003) Weight status, abdominal adiposity, diabetes, and early age-related lens opacities. Am J Clin Nutr 78: 400-405.

38. McCarty CA, Nanjan MB, Taylor HR (2000) Attributable risk estimates for cataract to prioritize medical and public health action. Invest Ophthalmol Vis Sci 41: 3720-3725

39. Grzybowski A (2005) The development of research on the effect of tobacco consumption on the visual organ over the last 200 years. Przegl Lek 62: 11671170.

40. Foster PJ, Wong TY, Machin D, Johnson GJ, Seah SK (2003) Risk factors for nuclear, cortical and posterior subcapsular cataracts in the Chinese population of Singapore: the Tanjong Pagar Survey. Br J Ophthalmol 87: 1112-1120.

41. Raju P, George R, Ve Ramesh S, Arvind H, Baskaran M, et al. (2006) Influence of tobacco use on cataract development. $\mathrm{Br} \mathrm{J}$ Ophthalmol 90: 1374-1377.

42. Li WC, Kuszak JR, Dunn K, Wang RR, Ma W, et al. (1995) Lens epithelial cell apoptosis appears to be a common cellular basis for non-congenital cataract development in human and animals. J Cell Biol 130: 169-181.

43. Shinohara T, Ikesugi K, Mulhern ML (2006) Cataracts: role of the unfolded protein response. Med Hypotheses, 66: 365-370.

44. Ikesugi K, Yamamoto R, Mulhern ML, Shinohara T (2006) Role of the unfolded protein response (UPR) in cataract formation. Exp Eye Res 83: 508-516.

45. Mulhern ML, Madson CJ, Danford A, Ikesugi K, Kador PF, et al. (2006) The unfolded protein response in lens epithelial cells from galactosemic rat lenses. Invest Ophthalmol Vis Sci 47: 3951-3959.

46. Crowley-Weber CL, Dvorakova K, Crowley C, Bernstein $\mathrm{H}$, Bernstein $\mathrm{C}$, et al (2003) Nicotine increases oxidative stress, activates NF-kappaB and GRP78, induces apoptosis and sensitizes cells to genotoxic/xenobiotic stresses by a multiple stress inducer, deoxycholate: relevance to colon carcinogenesis. Chem Biol Interact 145: 53-66.

47. Klein BE, Klein R, Lee KE (1998) Diabetes, cardiovascular disease, selected cardiovascular disease risk factors, and the 5-year incidence of age-related cataract and progression of lens opacities: the Beaver Dam Eye Study. Am J Ophthalmol 126: 782-790.

48. Klein BE, Klein R, Moss SE (1995) Incidence of cataract surgery in the Wisconsin epidemiologic study of diabetic retinopathy. Am J Ophthalmol 119 295-300.

49. Kirby DB (1933) Cataract and diabetes. Arch Ophthalmol 9: 966-973.

50. Weintraub JM, Willett WC, Rosner B, Colditz GA, Seddon JM, et al. (2002) A prospective study of the relationship between body mass index and cataract extraction among US women and men. Int J Obes Relat Metab Disord 26 1588-1595.

51. Klein BE, Klein R, Lee KE, Jensen SC (2001) Measures of obesity and agerelated eye diseases. Ophthalmic Epidemiol 8: 251-262.

52. Chatterjee A, Milton RC, Thyle S (1982) Prevalence and aetiology of cataract in Punjab. Br J Ophthalmol 66: 35-42.

53. Zhang F, Chen Y, Heiman M, DiMarchi R (2005) Leptin: structure, function and biology. Vitam Horm 71: 345-372.

54. Gômez-Ambrosi J, Salvador J, Frühbeck G (2004) Is hyperleptinemia involved in the development of age-related lens opacities? Am J Clin Nutr 888-889.

55. Yamagishi S, Amano S, Inagaki Y, Okamoto T, Takeuchi M, et al. (2003) Pigment epithelium-derived factor inhibits leptin-induced angiogenesis by suppressing vascular endothelial growth factor gene expression through antioxidative properties. Microvascu Res 65: 186-190.

56. Narin F, Atabek ME, Karakukcu M, Narin N, Kurtoglu S, et al. (2005) The association of plasma homocysteine levels with serum leptin and apolipoprotein B levels in chilhood obesity. Ann Saudi Med 25: 209-214.

57. Kennedy RL, Chokkalingham K, Srinivasan R (2004) Obesity in the elderly: who should we be treating, and why, and how? Curr Opin Clin Nutr Metab Care 7: 3-9. 
Citation: Mvitu-Muaka M, Longo-Mbenza B, Mbadi A Nsungu NJ (2011) Relationship between Cataract and Metabolic Syndrome among African Type 2 Diabetics. J Diabetes Metab 2:160. doi:10.4172/2155-6156.1000160

58. Ford ES (1999) Body mass index, diabetes, and C-reactive protein among U.S. adults. Diabetes Care 22: 1971-1977.

59. Cushman M, Yanez D, Psaty BM, Fried LP, Heiss G, et al. (1996) Association of fibrinogen and coagulation factors VII and VIII with cardiovascular risk factors in the elderly: the Cardiovascular Health Study. Cardiovascular Health Study Investigators. Am J Epidemiol 143: 665-676.

60. Spector A, Wang GM, Wang RR, Li WC, Kleiman NJ (1995) A brief photochemically induced oxidative insult causes irreversible lens damage and cataract II. Mechanism of action. Exp Eye Res 60: 483-493.
61. Schaumberg DA, Ridker PM, Glynn RJ, Christen WG, Dana MR, et al. (1999) High levels of plasma $C$-reactive protein and future risk of age-related cataract. Ann Epidemiol 9: 166-171.

62. Ughade SN, Zodpey SP, Khanolkar VA (1998) Risk factors for cataract: a case control study. Indian J Ophthalmol 46: 221-227.

63. Shinohara T, White H, Mulhern ML, Maisel H (2007) Cataract: Window for systemic disorders. Med Hypotheses 69: 669-677. 